\title{
Sir Walter Scott, Benito PÉREZ GaLdós y la SÁTira QUIJOTESCA DE LAERUDICIÓN ${ }^{\mathrm{I}}$
}

\author{
Alfredo Moro Martín \\ Universidad de Cantabria
}

Title: Sir Walter Scott, Benito Pérez Galdós and the Quixotic Satire on Erudition

\begin{abstract}
The satire on excessive erudition counts with a long-standing tradition in Western Literature. From its Classical origins, the figure of the ridiculous erudite dunce exhibited a notable presence in the dramatic literature of the seventeenth century, being absorbed by the novel in the eighteenth, where it merges with the figure of the Quixote. The present article tries to relate the figures of Jonathan Oldbuck of Sir Walter Scott's The Antiquary (I 1 16) and José Augusto Becerro, of Benito Pérez Galdos' El caballero encantado (1909) with this literary archetype, revealing the profound influence of the eighteenth-century Cervantean tradition in the work of both authors, who employ the Quixotic erudite dunce in similar ways in order to satirize an outdated approach towards the study of history and its narrative embodiment.
\end{abstract}

Key words: Cervantes. Scott. Galdós. Historical Novel. Quixotism. Satire on Erudition. Comparative Studies.

1. Introducción: Consideraciones iniciales Sobre EL tiPo. De LA SÁTIRA DE LA ERUdición AL PEDANTE QUiJOTESCO

La ridiculización de la erudición excesiva cuenta con una larga tradición en las letras occidentales. Para Elizabeth Frenzel, la figura del erudito ridículo se enmarca dentro de la categoría más amplia del estrafalario o Sonderling, caracterizado por un comportamiento fuera de lo normal, por una "inadaptación parcial y una extravagancia que les da un aspecto patético y ridículo” (1994: I 38). Según la investigadora germana, estos personajes suelen convertirse en símbolos de "inclinaciones no generalizadas", de "ideas que han dejado o que no son propias del común de la gente” (I 994: I 38), por lo que el arquetipo es generalmente empleado para satirizar desviaciones de la norma o comportamientos ridículamente anacrónicos.

${ }^{\mathrm{I}} \mathrm{La}$ investigación en la que se basa este proyecto se ha realizado en el marco del Proyecto de I+D de Generación del conocimiento del Programa Estatal del Ministerio de Ciencia, Innovación y Universidades titulado "El Quijote transnacional” (PGC2O 8-093792-B-

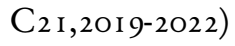


Nos encontramos, en cualquier caso, ante una figura de una extraordinaria diversidad tipológica, ya que las rarezas del Sonderling son tan variadas como lo son los objetivos satíricos perseguidos por los autores que la emplean. Los primeros pasos del erudito estrafalario, o del avatar libresco del Sonderling, pueden encontrarse en la comedia erudita italiana de mediados del siglo XVI, en la que autores como Francesco Bello (Il pedante, i 529 ) o Pietro Aretino (Il flosofo, I 546) crean un tipo de comedia basada específicamente en figuras un tanto demodés y que demuestran "una verbosidad fatua, ampulosa, anquilosada, plagada de frases y citas latinas" (Frenzel i 994: I40), evidenciando un comportamiento fundamentalmente libresco que articula una clara distancia entre el pedante erudito y el resto de personajes, separación que es explotada con fines cómicos y satíricos. El estrafalario erudito pronto pasará al terreno de la commedia dell'arte, confluyendo en el personaje del dottore, figura que contará con un gran predicamento en el teatro francés de principios del XVII, aunque con objetivos ligeramente distintos a los del pedante erudito, ya que generalmente se resalta la hipocresía de estos "hombres de libros", aparentemente dedicados en cuerpo y alma a las más altas empresas del espíritu, pero en realidad volcados en los placeres sensuales. Esta transformación francesa del tipo, por lo tanto, no puede ser más distinta de los eruditos librescos de Bello o Aretino. ${ }^{2}$

Durante el siglo XVIII la figura del pedante erudito resurgirá con renovados bríos y, si bien pervive en las tablas de los teatros, donde había dado sus primeros pasos, pronto encontrará un espacio mucho más propicio en el género literario que comienza a adquirir un impulso imparable, la

${ }^{2}$ Como exponentes de esta tendencia, Frenzel (I994: I40) reseña las obras de P. de Lavirrey (La Constance, I6 I , y Le Fidelle, de ese mismo año), mediador del teatro italiano en Francia e introductor de la figura del pédant; así como la presencia del tipo en la obra de destacados autores franceses de la centuria como Cyrano de Bergerac (Le Pédant joné, 1654) o Paul Scarron (Le Capitaine matamore et Boniface pédant, I647). 
novela. ${ }^{3}$ Tal y como ha apuntado Pedro Javier Pardo en un magnífico estudio sobre la sátira quijotesca de la erudición en la literatura inglesa de esta centuria, el siglo XVIII fue un momento histórico claramente transicional entre dos concepciones bien distintas del conocimiento, algo que favorecerá el desarrollo del género de la sátira de la erudición:

$[\ldots]$ why did satire on learning flourish in the eighteenth century? The answer must obviously be sought in the transitional nature of the age, which was one of conflict between old learning, scholastic and pseudo-scientific knowledge based on authority and religious revelation on the one hand, and, on the other, the modern forms of knowledge based on reason and experimentation which, under the influence of philosophers and thinkers such as Bacon or Descartes, were emerging in the late seventeenth century as well as in the eighteenth. (2004: 7)

Este conflicto entre dos maneras antagónicas de abordar el conocimiento generó, por lo tanto, un caldo de cultivo propicio para la crítica de las desviaciones de la norma establecida en torno al concepto de erudición, bien sea por el exceso de ésta, por su anacronismo, o por su aplicación a contextos inapropiados o ridículos. Esta tendencia puede rastrearse antes del siglo XVIII no sólo en los dramaturgos anteriormente mencionados, sino también en autores de poemas paródicos como Samuel Butler, que además de retratar los excesos de celo religioso a través del protagonista de su Hudibras (1663-1678), abordó específicamente la cuestión en sus obras The Elephant in the Moon (1670-167 I) y Satire in Two Parts upon the Imperfections and abuse of Human Learning (1670-1671), tal y como ha señalado Pardo (2004: 2). ${ }^{4}$ Pese a su destacada presencia en el siglo XVII, el siglo XVIII se-

${ }^{3}$ Por ejemplo, la presencia del pedante erudito en la dramaturgia alemana del siglo XVIII es bastante destacable. Obras como Die zärtlichen Schwestern (1747) de C.F. Gellert, Der junge Gelehrte (1748), de G.E. Lessing o Der Hofmeister (1774), de J.M.R. Lenz, cuentan con eruditos pedantes de carácter ridículo.

${ }^{4}$ En este sentido, hay que destacar que el teatro inglés del siglo XVII también experimentó con la figura del Virtuoso, presente en la obra homónima de Thomas Shadwell (1676), que Pardo define como "an evident fore-runner of the eighteenth-century pedant" (2004: 3). 
rá el momento en el que la figura del pedante erudito adquiera un mayor desarrollo, y lo hará en varias literaturas europeas.

En Gran Bretaña, los autores del llamado Scriblerus Club, Alexander Pope, Jonathan Swift, el doctor Arbuthnot, Thomas Parnell y John Gay, dan forma en sus Memoirs of Martinus Scriblerus (174I) a la figura de Martinus Scriblerus, el avatar más logrado del pedante erudito, en palabras de Pardo "the model or paradigm of the genre" (2004: 4). La influencia de Scriblerus puede sentirse en toda una serie de eruditos ridículos que irán apareciendo en la novelística inglesa del XVIII. Así, Henry Fielding introduce las figuras de los tutores Thwackum y Square en su Tom Jones (1749), mientras que Charlotte Lennox en el Female Quixote (1752) caricaturiza al pedante Mr. Selvin. Por su parte, Samuel Johnson introduce la figura del astrónomo con pretensiones de erudición en su Rasselas de 1759 (Pardo 2004: 3). La ridiculización de la figura alcanzará, sin embargo, su punto álgido, en los inolvidables Walter y Toby Shandy de The Life and Opinions of Tristram Shandy, Gentleman (176I-1767), del novelista anglo-irlandés Laurence Sterne, novela en la que las obsesiones de ambos personajes por la castrametación y por la educación preceptiva llevan la sátira del conocimiento excesivo o aplicado a contextos ridículos hasta sus últimas consecuencias. Otras obras menores como Learning at Loss (1778), del hoy olvidado Gregory Lewis Way, inciden de nuevo en el tipo, demostrando cómo la figura contó con una excelente salud durante toda esta centuria.

En cualquier caso, tal y como destaca Pardo (2004: 3), el fenómeno no es exclusivamente británico, sino que cuenta con una clara dimensión europea. En su estudio, el profesor de la Universidad de Salamanca cita ejemplos franceses como la Histoire de Monsieur Ouffle (1 7 I 10$)$, del abate Laurent Bordelon, la anónima Le Chef-d'ouvre d'un Incconu (I 7 I4); o las Memoirs de l'Academie de Troyes (1744), de Pierre-Jean Grosley. En España, Pardo reseña la conocida obra del Padre Isla, Fray Gerundio de Campazas (1758-1768), Los 
eruditos a la violeta (1772) de José Cadalso y el Don Quijote el Escolástico (1788-1789) de Pedro Centeno. Al exhaustivo repaso ofrecido por Pardo se podrían añadir algunas obras germanas que también emplean el tipo, como la parodia richardsoniana de J.A.K. Musäus, Grandison der Zweite (I760I762), en la que además del quijotesco Herr v. Neuhorn, obsesionado con replicar en su hacienda rural todo el universo novelesco de la History of Sir Charles Grandison (1753) de Samuel Richardson, nos encontramos con el no menos quijotesco Magister Lampert, figura que trufa su discurso de latinismos y referencias eruditas, y que supone una de las más logradas figuraciones del tipo en la Alemania dieciochesca. A Lampert podrían sumarse otras figuras como el Magister Sebaldus Nothanker, de la novela Das Leben und die Meinungen des Herrn Magister Sebaldus Nothanker (1773), en la que Christoph Friedrich Nicolai traza una figura muy sterniana, obsesionada con la mística de los números o con diversas extravagancias religiosas (Frenzel, I 994: I42); sin olvidar las excéntricas figuras del principal seguidor de Sterne en la Alemania dieciochesca, Jean Paul Richter, que explora las figura del pedante erudito o del monomaniaco libresco a lo largo de toda su producción novelística. ${ }^{5}$

Del repaso a las fortunas de la figura en las letras europeas de los siglos XVII y XVIII pueden deducirse dos tendencias fundamentales, ya apuntadas por Pardo. La primera es la permeabilidad del arquetipo del pedante erudito por otra figura que contará con un amplio desarrollo durante esta centuria, y que no es otra que la del Quijote, que genera durante este pe-

${ }^{5}$ En este sentido, como señala Frenzel (I 994: I 42) cabría destacar figuras como el ausente Freudel (Des Amts-Vogts Josuah Freudel Klaglibell gegen seinen verfluchten Dämon, I79r), el pedante Fälbel de la novela Des Rektors Florian Fälbel Reise nach dem Fichtelberg, I 791), el obsesivo Quintus Fixlein, aficionado a los oráculos y que cree firmemente en que la fecha de su muerte está determinada por éstos (Leben des Quintus Fixlein, aus fünfzehn Zettelkästel gezogen), o el fanatismo del Dr. Katzenberger por las ciencias naturales (D. Katzenberger Badereise, i 809). Al igual que en Sterne, nos encontramos ante personajes obsesionados por una monomanía libresca y erudita, que define absolutamente todos los aspectos de la existencia de los personajes en cuestión. 
riodo una gran diversidad de formas y tipos, adaptados todos ellos a una multiplicidad de fines satíricos. ${ }^{6}$ En segundo lugar, cabe destacar el carácter transnacional y si se me permite el neologismo, transecular, de esta figuración literaria. El pedante erudito nace en el siglo XVII y encuentra su máximo desarrollo en el siglo posterior por las condiciones históricas destacadas anteriormente, pero recorrerá nuevas sendas en los siglos XIX y XX gracias a la novelística de autores como Carlyle, Dickens, Flaubert, Nabokov o Joyce, tal y como apunta Pardo (2004: 2) con la amplitud de mirada que le caracteriza. ${ }^{7}$

El objetivo de este artículo es, por lo tanto, profundizar en el estudio del carácter transnacional del tipo y su destacada presencia en las centurias posteriores al siglo XVIII, los siglos XIX y XX. A través del análisis de The

${ }^{6}$ Así lo señala Pardo en un artículo anterior (1998) dedicado a la sátira quijotesca de la pedantería en la literatura francesa del siglo XVIII, en el que se destaca la convergencia entre Don Quijote y su primo humanista, otro erudito satirizado, en la sátira de erudición francesa de esta centuria:

En cualquier caso, aun no reconociendo esta afinidad y considerando a don Quijote y al humanista como figuras claramente separadas, es indiscutible su convergencia en la figura del pedante que aparece en algunas obras inglesas y francesas del siglo XVIII, de antecedentes rabelaisianos pero de naturaleza claramente quijotesca. Se trata siempre de un hombre empapado de literatura, aunque en este caso no ficción sino un conjunto de heterogéneos saberes literarios, filosóficos, históricos, que le conducen a empresas igualmente disparatadas y excéntricas, en las que se trasluce una visión igualmente distorsionada de la realidad, y cuya comicidad, basada en el contraste entre sujeto y objeto -o método y contenido- de la empresa, da lugar a la sátira. (I 50)

7In carrying out this task, this paper will (I) focus on the existence of English, French and Spanish works which testify to the European dimension of the genre and to a shared critical conception of learning as pedantry. It will then (2) draw a composite portrait of the central figure, the pedant, virtuoso, learned wit, or erudite dunce, who gives unity to the works themselves and to the genre as a whole, and it will demonstrate his indebtedness to the Quixotic figure. And, it will finally (3) suggest lines of research which may render the topic interesting and fruitful, it will hint how this genre may be explored through a comparative approach which should highlight its supranational dimension and permanence through different periods and ages, and at the same time underscore the differences arising from different contexts, both temporal and spatial. (Pardo, 2004: 2, énfasis añadido) 
Antiquary (1816), de Sir Walter Scott, y de la a veces infravalorada El caballero encantado (1909), de Benito Pérez Galdós, pretendo resaltar cómo el pedante quijotesco cuenta con una destacada presencia en la obra de dos autores íntimamente relacionados como el novelista escocés y el autor canario. El estudio comparativo de las figuras de Jonathan Oldbuck y José Augusto Becerro nos permitirá vislumbrar cómo Scott y Galdós continúan con la tradición de eruditos de carácter quijotesco tan brillantemente explotada por el siglo anterior, explicitando cómo algunas de las tendencias ya presentes en la tradición cervantina dieciochesca cuentan con una clara continuación en autores decimonónicos de una extraordinaria relevancia para ulteriores desarrollos del género. Como se tratará de demostrar en las páginas que siguen, Oldbuck y Becerro comparten un origen común, pero serán empleados por Scott y Galdós para reflejar sus actitudes personales respecto al conocimiento del pasado y su relevancia para el presente, un tema absolutamente fundamental en la obra de estos dos novelistas.

2. "The MOST DETERMINED, AS WELL AS EARLIEST BIBLIOMANiAC UPON RECORD". JONATHAN OLDBUCK Y LA SÁTIRA QUIJOTESCA DE LA ERUdición en The Antiquary (1816), DE Sir Walter Scott

Como ha destacado Pardo, la figura del Quijote ofrece un patrón ficcional de locura y monomanía literarias que ya se encontraba en el germen mismo de la figura del pedante erudito (2004: 5), por lo que la aleación de la figura quijotesca con la sátira de la erudición resulta completamente natural. Para Pardo, el pedante erudito muestra una serie de rasgos quijotescos que creo conveniente destacar antes de abordar el análisis de las figuras de Jonathan Oldbuck y José Augusto Becerro. En primer lugar, el pedante erudito, al igual que el Quijote, evidencia una monomanía literaria, en este caso no de carácter romancesco-caballeresco, sino más bien de tono erudito, aunque a veces ambas pueden llegar a converger. Además de esta monomanía erudita, el pedante quijotesco suele embarcarse en empresas ridículas o ex- 
céntricas, de nuevo relacionadas con sus saberes e intereses librescos (2004: 6). Junto a estas dos características, el pedante erudito comparte con la figura del Quijote una visión librescamente distorsionada de la realidad, que normalmente suele implicar una ridiculización de las fuentes de su saber:

The pedant, like Don Quixote, sees everything framed by an intellectual pattern, through the lenses of his bookish worldview, and these refract a warped image. In the second place, this distortion of reality goes hand in hand with the burlesque or ridiculing of its sources. (2004: 6)

También cabría destacar que el pedante erudito suele simplificar la complejidad de la vida en sistemas rígidos y cerrados, y contaminar los aspectos más simples de ésta por su visión eruditamente deformada de la realidad, que le lleva a generar los más complejos sistemas abstractos para explicar acontecimientos o hechos de causas bien sencillas (6). A su vez, a las características reseñadas por Pardo cabría añadir que esta monomanía erudita de carácter libresco resulta fundamental también en el lenguaje empleado por este tipo de estrafalarios librescos, ya que éste siempre se ve trufado de latinismos, cultismos y referencias oscuras que generan una distancia comunicativa entre el resto de personajes y el Quijote erudito de turno. Únicamente aquellos personajes que comparten el universo referencial del pedante quijotesco pueden enfrascarse en un debate con él, y precisamente la rigidez mental de estas figuraciones literarias suele desencadenar cómicas discusiones en torno a las cuestiones más abstrusas y ridículas.

En The Antiquary (1816), su tercera novela, Walter Scott va a dar forma a esta aleación entre erudición y quijotismo a través de la figura de Jonathan Oldbuck. ${ }^{8}$ De hecho, Oldbuck deja claro su carácter excéntrico y erudito en su primera aparición en la novela. Su primer encuentro con

${ }^{8}$ El propio apellido del personaje, Oldbuck, parece una cómica declaración de intenciones por parte de Scott, ya que fonéticamente resulta extremadamente similar a old book, o libro antiguo. El hecho de situar los orígenes de la familia de Oldbuck en uno de los primeros impresores germanos seguidores de Johannes Gutenberg parece resaltar la naturaleza impresa, textual de este personaje. 
el otro protagonista de la obra, el joven inglés Lovel, con el que Oldbuck coincide a la espera de una diligencia, se ve claramente marcado por los hábitos librescos del anticuario, mediante los que Scott lo caracteriza como un claro pedante erudito. En primer lugar, ante el retraso de la diligencia de Queensferry y la sorpresa de Lovel, Oldbuck expresa su disgusto por no haber dispuesto de un poco más de tiempo para cerrar un acuerdo respecto a unos manuscritos (I4-I 5). El retraso pronto permite a Lovel apreciar la jerga latinizante y judicial que Oldbuck emplea con la taquillera de la diligencia, generando una situación ciertamente cómica propiciada por la disparidad entre las razones legales aducidas por el anticuario y la incomprensión de su verborrea latina por parte de la humilde empleada de la diligencia (17). ${ }^{9}$ Esta presentación libresca se ve completada una vez que Lovel y Oldbuck se encuentran finalmente dentro de la diligencia. La pedantería y el amateurismo de Oldbuck son resaltados por la mirada irónica del narrador, que se sirve del folio recientemente adquirido por Oldbuck para presentar su particular monomanía erudita, la arqueología y antigüedades romanas y pictas en el norte de Gran Bretaña, particularmente en Escocia:

By degrees, however, his wrath subsided; he wiped his brows, relaxed his frown, and, undoing the parcel in his hand, produced his folio, on which he gazed from time to time with the knowing look of an amateur, admiring its height and condition, and ascertaining, by a minute and individual inspection of each leaf, that the volume was uninjured and entire from title-page to colophon. His fellow-traveler took the liberty of inquiring the subject of his studies. He lifted up his eyes with something of a sarcastic glance, as if he supposed the young querist would not relish, or perhaps understand, his answer, and pronounced the book to be Sandy Gordon's Itinerarium Septentrionale, a book illustrative of the Roman remains in Scotland. The querist,

${ }^{9}$ Las continuas referencias legales y latinas que trufan el discurso de Oldbuck tienen una explicación en su carrera frustrada como abogado, que, según el narrador, parece el origen de sus intereses eruditos, ya que "he made himself master of the whole forms of feudal investitures, and showed such pleasure in reconciling their incongruities, and tracing their origin, that his master hoped that he one day would be an able conveyancer" (24). El narrador destaca cómo Oldbuck jamás fue capaz de aplicar este conocimiento a propósitos prácticos o lucrativos (24), por lo que podemos observar claramente la clara tendencia del pedante erudito quijotesco a disociarse de la realidad y vivir en un mundo fundamentalmente libresco. 
unappalled by this learned title, proceeded to put several questions [...] The elder traveler, observing with pleasure the capacity of his temporary companion to understand and answer him, plunged, nothing loath, into a sea of discussion concerning urns, vases, votive altars, Roman camps, and the rules of castramentation. ( 18 )

El lector despierto pronto reconocerá en la obsesión por las reglas de la castrametación un claro paralelismo con otro célebre pedante quijotesco de la tradición cervantina británica, el Toby Shandy de Laurence Sterne. En cualquier caso, Lovel pronto podrá comprobar la profunda distorsión de la realidad que esta monomanía erudita propicia en Oldbuck. Aduciendo un falso interés por el bienestar de los caballos de la diligencia, necesitados de un descanso, Oldbuck aprovecha una pequeña pausa en el viaje para llevar a Lovel a lo que él considera como un claro campamento picto, algo que acarrea que ambos pierdan el ferry al que se dirigían en la diligencia por el retraso causado por la interrupción (19-20). Este inconveniente parece no importunar demasiado a Oldbuck, que, habiendo encontrado una víctima propicia, se ve encantado de explicar las diferencias entre la manera de atrincherar un castra stativa y el diferente castra aestiva (20), entre otras disquisiciones eruditas.

Ante la lógica y esperada pérdida del ferry, Oldbuck invita a Lovel a realizar una visita a su hogar, un antiguo monasterio reconvertido en residencia doméstica. Su propio domicilio, Monkbarns, se presta a las especulaciones eruditas del anticuario, ya que ante una de las observaciones de Lovel, que ve en una piedra inscrita con las letras LV la mitra de un obispo, el anticuario elabora toda una disquisición erudita que acaba relacionando la supuesta mitra con el Obispo de Trotcosey, o Abbas Trottocosiensis (3 I). De un comentario puramente ocasional de Lovel, Oldbuck genera una compleja y disparatada teoría anticuaria, demostrando una clara tendencia a aprehender la realidad que le rodea bajo el filtro de su propia erudición. ${ }^{\text {Io }}$

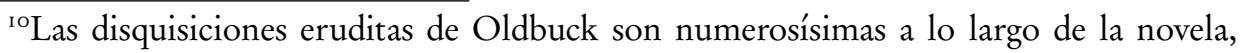
ya que el personaje siempre muestra su erudición cuando tiene ocasión de hacerlo. Así, 
Como señala Ina Ferris, el anticuario acaba convirtiéndose en una "strangely extopic creature who primarily lives in-and almost as-text” (2002: 28I).

Scott continúa la caracterización libresca de su personaje a través de la descripción de su biblioteca, que constituye un magnífico ejemplo de una suerte de síndrome de Diógenes anticuario no demasiado diferente al que uno puede encontrarse en Abbotsford, la residencia de Walter Scott. ${ }^{11}$ Allí, Oldbuck muestra a Lovel un bastón de un tamaño considerable, que pese a tener la clara apariencia de ser uno de los cayados que los jornaleros de las Highlands emplean en sus peregrinaciones anuales desde la montaña (The Antiquary: 34), es interpretado por el anticuario como una de las armas con las que los monjes que habitaron la propiedad armarían a sus siervos en caso de conflicto, hecho que les granjeó el apelativo de Colve-Carles, relacionado con el germano Kolb-kerl, o portadores de palos. La discrepancia entre la realidad inmediata y el mundo erudito de Oldbuck no puede ser mayor, y demuestra la tendencia del protagonista de Scott a apreciar el mundo circundante a través de la lente de su erudición, que permea todo su discurso y su visión del mundo.

Oldbuck da rienda a sus elucubraciones lingüísticas en torno al origen de la palabra "Shathmonth" (84) o del topónimo "Quickens-bog" (34I); nos muestra sus conocimientos de demonología y brujería al hacer referencia a una crónica de apariciones del siglo XVII para explicar cómo se debe narrar una historia de aparecidos (9I); o aporta una serie de digresiones anticuarias sobre el cuerno de la abundancia (229) o los ritos funerarios de los antiguos escandinavos (292) al conversar en un funeral con M'Intyre sobre los posibles destinos del soldado en las guerras europeas que tienen lugar en el momento histórico en el que Scott sitúa su novela.

${ }^{1}$ Sobre la biblioteca como espacio de caracterización libresca en la tradición cervantina puede consultarse la magnífica contribución de José Montero Reguera (20 r 8: 45-69). 
Significativamente, estas muestras de erudición y la pasión de Oldbuck por sus libros son vinculadas claramente por Scott con la figura de Don Quijote de la Mancha, al que el narrador denomina como "el primer bibliomaniaco del que se tiene constancia":

$[\ldots]$ it was chiefly upon his books that he prided himself. [...] The collection was indeed, a curious one, and might well be envied by an amateur. Yet it was not collected at the enormous prices of modern times, which are sufficient to have appalled the most determined, as well as earliest bibliomaniac upon record, whom we take to have been none else than the renowned Don Quixote de la Mancha, as, among other slight indications of an infirm understanding, he is stated, by his veracious historian, Cid Hamet Benengeli [sic], to have exchanged fields and farms for folios and quartos of chivalry. In this species of exploit, the good knight-errant has been imitated by lords, knights, and squires of our own day, though we have not yet heard of any that has mistaken an inn for a castle, or laid his lance in rest against a windmill. Mr Oldbuck did not follow these collectors in such excess of expenditure, but taking a pleasure in the personal labour of forming his library, saved his purse at the expense of his time and toil. (34-35, énfasis añadido)

La referencia al Quijote no resulta aleatoria, ya que vincula la figura del pedante erudito con la de Alonso Quijano, que se convierte en un claro precedente ficcional para Oldbuck, estableciendo una clara genealogía cervantina para el anticuario de Scott. ${ }^{12}$ Esta asociación, de una importancia

${ }^{12}$ La bibliografía sobre influencia de Cervantes en la obra de Scott es amplia. A los estudios clásicos de Clara Snel-Wolfe (1932) y McDonald Jr (1959), cabría sumar las contribuciones de Alexander Welsh (I98I), Theodor Wolpers (I 986), Wolfgang G. Müller (I988), y Heinz-Joseph Müllenbrook (1999), que han abordado desde diferentes perspectivas el papel que Don Quijote juega en Waverley, or 'Tis Sixty Years Since (1814), la primera novela de Scott. Más recientemente, Pedro Javier Pardo ha analizado la influencia de Don Quijote en Waverley desde el prisma de la conexión que surge a finales del siglo XVIII y principios del XIX entre literatura de viajes y literatura cervantina (2014), así como el nuevo tipo de héroe quijotesco decimonónico que Scott crea en la figura de Edward Waverley (2016); mientras que yo mismo he reivindicad el papel del autor escocés dentro de la recepción de Cervantes en las letras británicas (2016, 2017). Las primeras décadas del siglo XXI han visto un aumento de los estudios por parte de la crítica cervantina respecto a la novelística de Scott, y las contribuciones de Robert ter Horst (2000), Michael Gerli (2005) y Howard Mancing (2009) reflejan este creciente interés. Ter Horst ha analizado las afinidades entre la obra de Cervantes y la del autor escocés, así como su similar relación inclusiva respecto al romance. Por su parte, Gerli ha estudiado la utilización por parte de Scott en relación 
fundamental en la novela, emparenta explícitamente al protagonista de The Antiquary con la tradición de la sátira quijotesca de la erudición tan brillantemente desarrollada a lo largo del siglo XVIII. Como trataré de argumentar a continuación, la tercera novela de Scott supone un destacadísimo ejemplar de esta transformación del mito quijotesco que, partiendo de los hallazgos satíricos articulados en torno a la figura del pedante erudito durante la centuria anterior, encuentra en The Antiquary una brillante materialización que responde a la preocupación de Scott por la apropiación amateur del conocimiento anticuario durante las primeras décadas del siglo XIX.

En cualquier caso, la caracterización quijotesca de Oldbuck no se limita a la significativa referencia cervantina del narrador. En el capítulo cuarto, en una de las excursiones anticuarias en las que Lovel se embarca junto a Oldbuck, el lector puede encontrar un magnífico ejemplo de la tendencia del anticuario a establecer teorías arqueológicas completamente alejadas de la realidad. En el Quijote, Cervantes articula un continuo diálogo entre la imaginación transformativa del hidalgo manchego y la función de correctivo epistemológico generalmente llevada a cabo por Sancho Panza. En The Antiquary, Scott se sirve de un procedimiento similar para evidenciar la erudición imaginativa del anticuario al transformar un antiguo refugio para mendigos rehabilitado para la celebración de una boda entre campesinos en lo que él denomina como el Kaim of Kimprunes, un supuesto castro romano en el que Agrícola habría situado el campamento romano en su batalla frente a los belicosos caledonios:

'You must know,' he said, 'our Scottish antiquaries have been greatly divided about the local situation of the final conflict between Agricola and the

a sus propios planteamientos sobre la legitimidad del género de la novela a principios del siglo XIX; mientras que Mancing, limitado al contexto de un capítulo sobre la recepción de Cervantes en Gran Bretaña durante los siglos XIX y XX, destaca la fascinación del autor escocés por Cervantes y ciertos paralelismos entre la obra de ambos autores. 
Caledonians [...] Now, after all discussion,' continued the old gentleman, with one of his slyest and most complacent looks, 'what would you think, Mr Lovel, -I say, what would you think,-if the memorable scene of conflict should happen to be on the very spot called the Kaim of Kinprunes, the property of the obscure and humble individual who now speaks to you?'Then, having paused a little, to suffer his guest to digest a communication so important, he resumed his disquisition in a higher tone. 'Yes, my good friend, I am indeed greatly deceived if this place does not correspond with all the marks of that celebrated place of action. It was near to the Grampian mountains-lo! Yonder they are, mixing and contending with the sky on the skirts of the horizon!-it was in conspectus classis-in sight of the Roman fleet; and would any admiral, Roman or British, wish a fairer bay to ride in than that on your right hand? It is astonishing how blind we professed antiquaries sometimes are; [... I I was unwilling to say a word about it till I had secured the ground, for it belonged to auld Johnnie Howie, a bonnetlaird hard by, and many a communing we had before he and I could agree. At length-I am almost ashamed to say it-but I even brought my mind to give acre for acre of my good corn-land for this barren spot [... I I began to trench the ground, to see what might be discovered; and the third day, sir, we found a stone, which I have transported to Monkbarns, in order to have the sculpture taken off with plaster of Paris, it bears a sacrificing vessel, and the letters A.D.L.L. which may stand, without much violence, for Agricola Dicavit Libens Lubens. (4I) ${ }^{\text {I3 }}$

${ }^{13}$ La teoría erudita de Oldbuck en torno al castro se ve pronto refutada por Edie Ochiltree, el vagabundo de la novela que generalmente actúa como correctivo epistemológico para algunas de las disparatadas teorías de Oldbuck. La inscripción A.D.L.L., que en teoría certificaba la edificación del castro por Agrícola, viene a significar Aiken Drum's Lang Ladle, ya que el lugar fue destinado a la celebración de la boda de Aiken Drum, uno de los proveedores de col para el mercado de Fife. El contraste entre la realidad degradada y las elevadas proyecciones eruditas de Oldbuck no puede ser mayor: 
El pasaje refleja bien a las claras el procedimiento transformativo de Oldbuck, que interpreta la realidad circundante bajo el prisma de su monomanía erudita, llegando a adquirir unos terrenos absolutamente inútiles a cambio de unas tierras fértiles para el cultivo del maíz, en claro paralelismo con la venta de tierras por parte de Don Quijote para adquirir sus libros caballerescos. ${ }^{14}$ En ambos casos, la obsesión libresca huye de la practicidad

$\mathrm{Ou}$, I ken this about it, Monkbarns, and what profit have I for telling ye a lie-I just ken this about it, that about twenty years syne, I, and a when hallenshakers like mysell, and the mason-lads that built the lang dyke that gaes down the loaning, and twa or three herds maybe, just set to wark, and built this bit thin here that ye ca' the-the-Praetorian, and a' just for a bield at auld Aiken Drum's bridal, and a bit blithe gae-down wi' had in't, some sair rainy weather. Mair by token, Monkbarns, if ye howk up the bourock, as ye seem to have begun, ye'll find, if ye hae not fund it already, a stane that ane o'the mason-callants cut a ladle on to have a bourd at the bridegroom, and he put four letters on't, that's A.D.L.L. Aiken Drum's Lang Ladle-for Aiken was ane o' the kale-suppers o' Fife. (43-44)

Scott aplica un procedimiento similar ante el hallazgo de un cuerno, que Oldbuck interpreta inmediatamente como una cornucopia, o cuerno de la abundancia (229), mientras que Ochiltree, que de nuevo funciona como correctivo epistemológico, explica que el cuerno de carnero no es más que un recipiente para el rapé que intercambió por otro similar con un tal George Glen, minero (232). De manera similar, ante la destrucción de una pequeña urna, según Oldbuck el "lacrimatorio de Clochnaben", que el erudito considera como "the main pillar of my theory, on which I rested to show [...] that the Romans had passed the defiles of these mountains and left behind them traces of their arts and arms" (288), M'Intryre revela a Oldbuck que este supuesto "lacrimatorio" no es más que un pote de cerámica para enfriar el vino que pudo conseguir en una de las campañas en Egipto. (289)

${ }^{14}$ Esta no será la última vez que Oldbuck cierre un trato desfavorable por su ceguera anticuaria. Hacia el final de la novela, en el capítulo XVI, el narrador nos revela como un funcionario del ayuntamiento logró persuadir a Oldbuck para permitir la canalización del agua a través de su finca a cambio de unas piedras de la iglesia de St. Donagild, de poco valor:

They parted mutually satisfied; but the wily Clerk had most reason to exult in the dexterity he had displayed, since the whole proposal of an exchange between the monuments (which the council had determined to remove as nuisance, because they encroached three feet upon the public road,) and the privilege of conveying the water to the burgh through the estate of Monkbarns, was an idea which had originated with himself upon the pressure of the moment. (I5O) 
y del sentido común. Además, el pasaje demuestra cómo Oldbuck, pese a no haber vendido sus tierras para nutrir su biblioteca, como indicaba el narrador en el pasaje anteriormente mencionado, sí sacrifica una parte de su fortuna para satisfacer sus afanes anticuarios, que se ven culminados en su "Essay upon Castramentation", lectura encarecidamente recomendada a Lovel por el propio Oldbuck. Al igual que Walter Shandy, las empresas eruditas de Oldbuck se ven reflejadas también en una producción literaria que no sirve sino para satirizar la abundante literatura pseudo-erudita de un periodo en el que las ciencias históricas se encontraban en un paulatino proceso de institucionalización, evidenciando las prácticas anticuarias de Oldbuck como una suerte de quijotismo intelectual. ${ }^{\text {is }}$

Si bien la novela articula un claro contraste dialógico entre las teorías de Oldbuck y las explicaciones más pedestres de Ochiltree, en The Antiquary nos vamos a encontrar con otro procedimiento claramente cervantino ya desarrollado por algunos novelistas ingleses del XVIII como Henry Fielding o Laurence Sterne: la contraposición dialógica de monomanías u obsesiones eruditas de carácter extravagante completamente alejadas de la realidad. Si Fielding desarrollaba esta estrategia en su Tom Jones a través de las figuras de los preceptores Thwackum y Square, y Sterne hacía lo propio con los hermanos Shandy; Scott articula un triángulo de erudición quijotesca entre Sir Arthur Wardour, un noble empobrecido con pretensiones eruditas, el reverendo Blattergowl, obsesionado con el derecho eclesiástico, y el propio

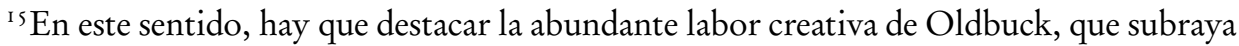
uno de los aspectos centrales del quijotismo erudito: la producción de tratados intelectuales de una clara naturaleza quijotesca. Así, amén de su tratado sobre la práctica del duelo (I 88I 89), escrito bajo el pseudónimo de Pacificator, Oldbuck reseña sus contribuciones a revistas anticuarias ( I 34). Además, aprovechando las aspiraciones poéticas de Lovel, Oldbuck insta al joven inglés a escribir un poema épico, la Caledoniada, en el que, cambiando el curso de la historia, los caledonios vencerían a las huestes romanas de Agrícola (I 34-I 35). Por supuesto, el aparato crítico y erudito correría a cargo de Oldbuck, y al poema se anexaría el ya mencionado Essay upon Castramentation.
} 
Oldbuck. Todos ellos, significativamente definidos por el narrador como “humoristas" (52), establecen una "disputa de narradores” ( I 84), en las que la realidad o cuestiones relacionadas con el pasado son interpretadas bajo una miríada de visiones eruditas, a cada cual más extravagante, convirtiendo algunos de los capítulos en un auténtico caleidoscopio interpretativo que revela el quijotismo anticuario de todos estos personajes.

En este sentido, el capítulo sexto de la novela supone un ejemplo antológico de esta tendencia a la confrontación dialógica de visiones eruditas de la realidad. En esta ocasión, la disputa se produce entre Oldbuck y Wardour, habitualmente enfrentados por el origen sajón o celta de los pictos, cuestión que ambos pedantes tratan de dirimir en torno a la etimología de la única palabra picta conservada hasta ese momento, el topónimo Benval. Para Oldbuck, el sufijo -val procede claramente del sajón wall, algo que le lleva a argumentar que el término significa "la cabeza del muro", ya que los pictos tomarían del celta el prefijo -ben, que como bien refiere Wardour, normalmente indica una colina o pequeña montaña (64). Por el contrario, el razonamiento de Sir Arthur Wardour es exactamente el opuesto. Empecinado en el origen celta del vocablo, para el noble escocés los pictos habrían asumido el sufijo -val del latino vallum, mientras que el original -ben garantizaría la procedencia celta de esta tribu de nebulosos orígenes (64). Como se puede observar, el origen de la palabra Benval se convierte en una suerte de baciyelmo lingüístico. Cada uno de los eruditos quijotescos cree ver en la palabra la confirmación de sus teorías eruditas en torno al origen de los pictos, una cuestión de no poca importancia para la construcción de la identidad escocesa. Finalmente, será el propio Lovel quien dirima la justa resaltando el carácter absurdo de la discusión, ya que Benval es la única palabra legada por los pictos, por lo que cualquier hipótesis sobre su origen cuenta con unas bases ciertamente endebles: 
'The Piks, or Picts,' said Lovel, 'must have been singularly poor in dialect, since, in the only remaining Word of their vocabulary, and that consisting only of two syllables, they have been confessedly obliged to borrow one of them from another language; and, methinks, gentlemen, with submission, the controversy is not unlike that which the two knights fought, concerning the shield that had one side white and the other black. Each of you claim one-half of the word, and seem to resign the other. But what strikes me most is the poverty of the language which has left such slight vestiges behind it.' (65)

El episodio resalta la absoluta cerrazón intelectual de ambos personajes, cada uno de ellos aferrado a su particular hobby-horse erudito y siempre dispuestos a justar con todo aquel que contradiga sus respectivos sistemas preconcebidos. ${ }^{16}$

El triángulo dialógico anteriormente mencionado encuentra una expresión certera en otra nueva confrontación erudita, la datación de las ruinas de la iglesia de St. Ruth, pertenecientes a las posesiones de Sir Arthur Wardour. En la discusión en torno a la fecha de construcción de la iglesia, cada uno de los tres caballeros andantes de la erudición aportará su particular visión del tema, siempre perfumada por sus propios intereses y visión del mundo. Oldbuck alude a una publicación reciente sobre antigüedades escocesas, el barón Wardour aporta todas las gestas heroicas de uno de los miembros de su árbol genealógico mencionado por Oldbuck; mientras que Blattergowl se centrará en el derecho eclesiástico, su área de especialización:

The Antiquary, starting like a war-horse at the trumpet sound, plunged at once into the various arguments for and against the date of 1273, which had been assigned to the priory of St. Ruth by a late publication on Scottish architectural antiquities. He raked up the names of all the priors who had ruled the institution, of the nobles who had bestowed lands upon it, and of the monarchs who had slept their last sleep among its roofless courts. As a train which takes fire is sure to light another, if there be such in the vicinity, the Baronet, catching at the name of one of his ancestors which occurred in Oldbuck's disquisition, entered upon an account of his wars, his conquests, and his trophies; and worthy Dr. Blattergowl was induced, from

${ }^{16}$ Así lo declara el propio Oldbuck cuando señala "I quarrel with no man's hobby, if he does not run in a tilt against mine, and if he does-let him beware his eyes." ( I I o). 
the mention of a grant of lands, cum decimis inclusis tam vicariis quam garbalibus, et nunquam antea separatis, to enter into a long explanation concerning the interpretation given by the Teind Court in the consideration of such a clause, which had occurred in a process for localling his last augmentation of stipend. The orators, like three racers, each pressed forward to the goal, without much regarding how each crossed and jostled his competitors. Mr. Oldbuck harangued, the Baronet declaimed, Mr- Blattergowl prosed and laid down the law, while the Latin forms of feudal grants were mingled with the jargon of blazonry, and yet the more barbarous phraseology of the Teind Court of Scotland. (I 83)

El episodio refleja el caleidoscopio de miradas eruditas sobre la realidad que Scott articula en su novela, confrontando a tres quijotescos jinetes montados en sus respectivos hobby-horses, continuando con una tradición dieciochesca iniciada por Fielding y Sterne, dos autores caros a Scott, tal y como lo demuestran sus juicios críticos y su destacada presencia en la biblioteca de Abbotsford. ${ }^{17}$

Finalmente, me gustaría señalar un último aspecto de la novela al que Scott apunta con su mirada satírica, y que me atreveré a denominar como erudición picaresca, o la falsa erudición empleada con intereses pecuniarios, epitomizada por Hermann Dousterswivel. Mediante la figura del "adepto” teutón, Scott nos presenta otra dimensión de los excesos de la erudición, o en este caso de la credulidad ante la pseudo-erudición de las teorías místicas y ocultistas tan en boga a finales del siglo XVIII y principios del XIX. Sir Arthur Wardour, apremiado por sus necesidades económicas, recurrirá a Dousterswivel para tratar de encontrar un tesoro que la tradición sitúa en la abadía de St. Ruth, ubicada dentro de sus dominios. El ocultista germano,

${ }^{17}$ Así lo atestigua el catálogo de Cochrane (i 838). En la biblioteca de Abbotsford pueden encontrarse novelas como Joseph Andrews, Tom Jones, Amelia o Jonathan Wild (I 838 : 63) e incluso sus obras completas, editadas por A. Chalmers en i 806 (I 838: i 88). En lo que se refiere a Sterne, amén del Sentimental Journey y de su Tristram Shandy (1838: 63), Scott también poseía una edición de sus obras completas y una biografía del autor anglo-irlandés (I 838: I 8 I). A todo esto debe sumarse la aproximación crítica y biográfica hacia estos autores por parte de Scott en sus Lives of the Novelists ( I 82 I- I 824), que contiene sendos capítulos dedicados a Fielding y Sterne. 
a cambio de una módica cifra y de un porcentaje de las ganancias, accede a compartir sus "conocimientos" con el crédulo Wardour, que queda absolutamente fascinado por la jerga ocultista y rosacruciana de Dousterswivel, en la que se mezcla la falsa erudición con el deseo de ganancia económica:

'You shall pardon me, my patron, it is not yet twelve, and twelve precise is just our planetary hours; and I could show you de spirit vary well, in de meanwhile, just for pleasure. You see I would draw a pentagon within a circle, which is no trouble at all, and make my suffumigation within it, and dere we would be like in one strong castle, and you would hold de sword while I did say de needful worts-Den you should see de solid wall open like de gate of ane city, and den-let me see-ay- you should see first one stag pursued by three black greyhounds, and they should pull him down as they do at de elector's great hunting-match-and den one ugly, little, nasty black negro should appear and take de stag from them-and paf-all should be gone-den you should hear horns winded dat all de ruins should ring-mine wort, they should play fine hunting piece, as goot as hium you call'd Fischer with his oboi-vary well-den come de great Peolphan, called the Mighty Hunter of the North, mounted on hims black steed-but you would not care to see all this? (209)

La jerga anglo-germana de Dousterswivel, repleta de las formulas simbólicas propias del discurso ocultista-cabalístico, se revela como un mero disfraz para engañar a un noble crédulo con aspiraciones de erudición y con necesidades económicas. De este modo, Scott refleja la cara menos amable de su sátira de la erudición. En los casos en los que Oldbuck se desprendía de sus bienes para adquirir antiguallas de poco valor, Scott empleaba una sátira amable y divertida del fenómeno; mediante las figuras de Dousterswivel y Wardour, el autor escocés muestra los peligros de la pseudo-erudición y cómo ésta, lejos de ser un pasatiempo quijotesco de carácter inofensivo, puede generar un espacio para todo tipo de pícaros dispuestos a aprovecharse de la credulidad de los estrafalarios librescos retratados en la novela.

De todo lo anteriormente expuesto se revela una mirada amable, pero no por ello menos crítica, respecto a unas formas de investigación histórica amateurizantes y en claro proceso de superación por parte de la historiografía institucionalizada. Como ha subrayado Ina Ferris, la novela de Scott 
se enmarca en un momento histórico de transición entre una concepción recreativa y diletante del conocimiento histórico, y su paulatina incorporación al resto de disciplinas universitarias:

This moment usually draws attention to the generic rivalry in the period between philosophical "conjectural" history, largely confined to the professionalizing and (at least in Scotland) urban institution of the universities, and antiquarian history, which remained primarily an amateur enterprise pursued mostly (but not exclusively) by leisured gentlemen in rural environs. (2002: 274)

La figura del anticuario se vio, por lo tanto, desplazada progresivamente por los géneros científicos "serios", siendo habitualmente acusada de deformar el conocimiento y de una clara pedantería (Ferris 2002: 274). Siguiendo esta tendencia, Walter Scott se erige como heraldo del paulatino ocaso de una especie en peligro de extinción a comienzos del XIX, que el novelista escocés retrata a través de sus quijotescos personajes y sus respectivos hobby-horses con una fina ironía no exenta de cierta compasión. De este modo, The Antiquary ofrece una clara reflexión en torno a la naturaleza y los límites del conocimiento anticuario, cuestionando su validez a la hora de ofrecer un retrato historiográfico serio. La sátira quijotesca de la erudición es transformada por Scott en un vehículo para separar claramente dos ámbitos bien diferenciados, la reconstrucción científica del pasado, por una parte, y por otra, la fascinación por éste y su empleo como base para la obra literaria. Tal y como apunta Lieve Behiels, en su novela, "Scott se despide de la historia filosófica, sintética y teleológica de la Ilustración y al mismo tiempo que se alinea a la nueva historia profesional, da paso a un modo de practicar la ficción historiográfica que influirá todo el siglo XIX” (2017: i I). Como lectores, podemos vernos embrujados por el hechizo del relato de tiempos pasados e incluso teñir el presente a través de sus heroicas reminiscencias, pero debemos, Scott parece sugerirnos, ser conscientes de que éste no deja de ser un divertimento estético. En caso contrario caeríamos en el terreno 
de la cerrazón intelectual y la pedantería, o del quijotismo erudito, precisamente la actitud a la que Scott dedica su tercera novela. Quizás, la manera más divertida de aproximarse a la historia sea a través de un historiador ficticio, sea éste arábigo o escocés. A este empeño dedicará Scott toda su carrera novelística, inaugurando un género de extraordinaria popularidad durante todo el siglo XIX y comienzos del XX, periodo en el que encontraremos a otro ilustre practicante del mismo, Don Benito Pérez Galdós.

\section{3. "Su vida toma jugo de la pura erudición". Augusto Bece- RRO Y LA SÁTIRA QUiJOTESCA DE LA ERUDICIÓN EN El CABALLERO encantado (1909), de Benito PÉRez Galdós}

La fascinación de Benito Pérez Galdós por Miguel de Cervantes, corroborada por el propio autor canario en las numerosas referencias y homenajes al alcalaíno que pueden encontrarse en sus novelas, así como por la presencia de numerosos volúmenes cervantinos en su biblioteca personal, ha sido habitualmente destacada por la crítica especializada. ${ }^{18}$ En uno de los primeros artículos científicos dedicados a esta, J. Warshaw señalaba a Galdós cómo "the logical-one might almost say the chronological successor to Cervantes in the novel" (1933: I 28), subrayando cómo casi todas las novelas del canario cuentan con un claro "sabor cervantino" (I 28). Por su parte, Rubén Benítez, en uno de los escasos estudios monográficos dedicado en exclusiva a la relación entre ambos autores, destaca cómo Cervantes es

${ }^{18}$ Warshaw (1933) y Obaid (1958) ofrecen un detallado panorama del conjunto de referencias al Quijote y a Cervantes por parte del autor canario. Sobre la relación entre ambos autores, amén de los estudios monográficos de Herman (I 955) y Benítez (I 990), pueden destacarse las contribuciones parciales de Latorre (I 947), Rodríguez (I 966), Goldman ( 197 I), Falconieri (1972), Elizalde (I991), y más recientemente, la tesis doctoral de Sara Alicia Fernández de Azcarate (2010) y la monografía de Penas Varela (2013), así como los artículos de Gullón (2004), Rivero Iglesias (2007), Dotras (2013) y Dorca (2016). Sobre el influjo cervantino de El caballero encantado, cabe reseñar el estudio de Julio Rodríguez Puértolas (I972). 
un referente fundamental para el arte novelístico de Galdós, quizás el más importante:

Sin Cervantes, su novelística sería otra o no existiría. Cervantes ilumina su pensamiento con respecto a España, le proporciona el modelo novelesco ideal, y le ayuda a incorporar críticamente las tendencias de la novela moderna de acuerdo con la tradición española y a apartarse de estas tendencias y superarlas cuando siente la insuficiencia o el desgaste de los principios que las generan. No hay otro caso igual de aceptación consciente y continuada de un escritor en otro escritor. Galdós se complace en destacar a cada momento su deuda con Cervantes, en un gesto admirativo que vale más que cualquier discurso crítico. (1990: 14)

Además de las constantes referencias al corpus literario cervantino o al propio autor alcalaíno, Benítez señala también el claro carácter quijotesco de muchos de los personajes galdosianos, aspecto en el que ya había incidido Warshaw, quien opina que Galdós deriva de Cervantes "his principles for the delineation of obsessed or pathological subjects" (I 933: I 27). Para Benítez, Galdós se sirve de la figura del Quijote para dar forma a toda una serie de tipos quijotescos que pueblan el universo novelístico del autor canario:

Lo mismo ocurre con los personajes ficticios. Hay entre ellos Quijotes de la Santidad, Quijotes políticos, Quijotes modernos, Quijotes del progreso, Quijotes de la economía y aún de la contabilidad, Quijotes de la agricultura, Quijotes de la Regeneración, Quijotes o "desfacedores de entuertos" de la antigüedad, Quijotes neoclásicos, Quijotes románticos, Quijotes guerreros, o periodistas o literatos. Muchos se parecen al Quijote por sus rasgos faciales, por su delgadez o estatura, y así se indica en cada caso. [...] No existe prácticamente novela de Galdós en que no aparezca algún personaje similar. (1990: I42)

De entre todos estos subtipos, caracterizados por "la frecuencia y abundancia de sus lecturas” (I990: 149), destaca la presencia en la novelística de Galdós lo que Benítez denomina como "Quijotes o desfacedores de entuertos de la antigüedad”. En su magnífico artículo, Behiels (2017) ya enmarcaba dentro de esta tendencia a figuras como el Cayetano Polentinos de 
Doña Perfecta (1 876) y el Buenaventura Miedes de Narváez (I 902), destacando cómo en ambos personajes el anticuarianismo se erige como una suerte de "cristal deformador a través del cual [se] mira la realidad" (2017: i 94), pero dejaba fuera de su estudio a Don José Augusto Becerro, el "erudito endemoniado" (El caballero encantado: rog) de la novela de Galdós. El objetivo de esta sección final de este artículo será precisamente completar las aportaciones de Behiels situando a Becerro dentro de la órbita del quijotismo erudito, analizando sus concomitancias con la tradición de la sátira de la erudición anteriormente analizada, con particular énfasis en las similitudes entre Becerro y el protagonista de The Antiquary.

Galdós nos presenta por primera vez al erudito José Augusto Becero en el círculo de amigos de Álvaro de Tarsis, el joven y ocioso noble que protagoniza El caballero encantado. En el segundo capítulo de la novela pronto se hace referencia al "sabio machacón” llamado José Augusto del Becerro, dedicado desde su más tierna infancia "a la enmarañada ciencia de los linajes, a desenredar madejas genealógicas y a bucear en el polvoroso piélago de los archivos" (82). Como destaca socarronamente el narrador, Becerro se encuentra predestinado a la erudición, no en vano "el hombre se sabía de memoria los becerros de todas las ciudades, monasterios y behetrías" (82). La descripción de la morada de Becerro, que se produce en el capítulo cuarto, contribuye a esta presentación del personaje como erudito libresco. Si Oldbuck era en parte definido por Scott a través de la amalgama de libros y antigüedades de Monkbarns, Galdós emplea un procedimiento similar al describir la morada de Becerro, que define como "caverna papirácea":

Nunca había estado Tarsis en la morada de Becerro, calle de Don Pedro, altísimo piso de una casa vieja y de grandes y desniveladas anchuras, que fue palacio de aristocracia hoy fenecida o aposentada en sitios más gratos. Llamó el caballero; le franqueó la puerta una persona que la oscuridad hizo invisible. Pisando baldosines rotos, que tecleaban con ruidillos que más parecían de risa que de llanto, llegó Carlos a la sala, toda libros, toda polvo, toda mugre, llena de cosas tuertas, cojitrancas y bizcas. Los estantes se caían de un 
lado, los rimeros de libros no tenían aplomo. Había desequilibrios inverosímiles, infolios que se balanceaban sobre rollos de balduque, papeles de mil formas acumulados sobre meses perláticas, y sostenidos, para que no los arrebatase el aire, por una mano de bronce o una pezuña de mármol. Ventana torcida y balcón ancho, desiguales en tamaño y forma, como un doble mirar oblicuo, daban paso a la claridad, verdosa del empaño de los vidrios.

Aunque en aquella caverna papirácea de inclinado techo no había esqueleto ni lechuza, ni retortas sobre hornillo, ni lagartos rellenos de paja, Tarsis creyó hallarse en la oficina del nigromante o alquimista que nos dan a conocer las obras de entretenimiento y las obras de magia. En un costado de la estancia, tras una mesa que desaparecía bajo la balumba de libros viejos y rancios papeles, emergía Becerro, dejando ver tan sólo medio cuerpo. Extremada era la delgadez exangüe de su rostro. A su amigo miró con ojos espantados, tardando un rato en reconocerle. (IO4)

Además de esta caracterización a través del espacio, las lecturas de Becerro también sirven para destacar el carácter profundamente anacrónico del personaje. En un pasaje que Galdós ofrece al lector en forma dramática, es el propio Becerro quien destaca sus quijotescos pasatiempos, vanagloriándose incluso del claro carácter demodé y exclusivo de la literatura con la que habitualmente se solaza:

BECERRO. (Más desmayado y mortecino que otros días. Su rostro fláccido, sus ojos plorantes, reviven al son claro de su palabra correctísima.)-El mismo procedimiento uso yo para huir de mis penas. En mis lecturas favoritas encuentro yo las aves que me llevan al retiro de los siglos que fueron. Ya sabes que el autor más moderno que leo es el arzobispo don Rodrigo Jiménez de Rada. También es de los míos el obispo don Lucas de Tuy. Me deleito en estos amenísimos autores; y cuando quiero mayor deleite, que a olvido mayor de lo presente me conduzca, echo mano del Fuero de Avilés, de los Fueros de Brañosera o Zorita de los Canes, de las escrituras de donaciones o fundaciones, o me extasío con el Cronicón Albeldense y con el Becerro de Santillana. (90)

Don Rodrigo Jiménez de Rada, un obispo de finales del siglo XII, o los fueros de la localidad campurriana de Brañosera, del siglo IX, no parecen las lecturas más actuales en el universo diegético de la novela, situada a comienzos del siglo XX, hecho que permite a Galdós incidir en el carácter ciertamente excéntrico y descontextualizado de los pasatiempos de don $\mathrm{Au}$ gusto. En una línea similar, cuando se discute el teatro contemporáneo en el 
capítulo tercero, Becerro declarará que no asiste a ningún estreno teatral, ya que ha decidido plantarse en Bartolomé Torres Naharro (93), enfatizando nuevamente la separación del erudito con el resto del mundo por el carácter anacrónico de sus lecturas dramáticas, en este caso algo más modernas, ya que la producción teatral de Torres Naharro se sitúa en las primeras décadas del siglo XVI. ${ }^{19}$

Al igual que Oldbuck, la obsesión libresca de Becerro le lleva a interpretar la realidad circundante a través de sus lecturas u obsesiones eruditas como la genealogía. Un claro ejemplo de esta tendencia es la disparatada teoría que establece en torno al origen de la casa de los Tarsis, que, en opinión del erudito, podría remontarse a Sem y Japhet:

Recibido el socorro, José Augusto rompió en estas explicaciones eruditas del apellido materno del caballero Tarsis. Descomponiendo y analizando el Suárez de Almondar, el maestro de linajes encontraba nombre y cognomen. El Suárez viene de Suero, el Suero de Asur, nombre semítico sin duda. De Almondar es corruptela del árabe Abo l'Mondar, que quiere decir Hijo del Victorioso. Reunidos y entramados estos nombrachos con el Tarsis, resultaban en una pieza las claras estirpes de Sem y Japhet, hijos del excelentísimo patriarca Noé. (83)

Estas disquisiciones eruditas, que recuerdan claramente a las teorías etimológicas de Oldbuck o Wardour, se ven contrapuestas dialógicamente

${ }^{19}$ Entre sus lecturas, Becerro tampoco hace ascos a las ciencias ocultas y a las artes hechiceriles, que considera de grandísimo entretenimiento:

Aquí tengo los autores españoles y extranjeros que tratan de magia y artes hechiceras, libros de tanta amenidad, que yo me los he leído cuatro veces de cabo a rabo, y aún he de gozar por quinta vez de tan entretenida y sabia lectura. Cógelos, apúralos hoja tras hoja, y pasarás ratos, horas, días, semanas y meses deliciosos.

Agradeció Carlos el obsequio, y se abstuvo de meter los ojos en aquel zarzal. Con prodigiosa memoria y sin abrir los mamotretos, Becerro le hizo cuento y noticia de ellos, a saber: Andrés Cesalpino, Jacobo Sprengero, Juan Niderio, Abad Gunfridus, que escribieron en latín, y don Sebastián de Covarrubias, definidor castellano del hechizo; el Padre Martín del Río, y el historiador Gonzalo Fernández de Oviedo, que refiere los artilugios maléficos de los indios. (IOS) 
con la visión del propio Gil-Tarsis sobre su genealogía. Pese al antiquísimo origen de su familia —siempre según Becerro-, Gil-Tarsis hubiera preferido unos orígenes algo menos ilustres, pero quizás más rentables económicamente:

- iY yo vengo de ese caballero... por cruce de la línea de los Tarsis, nieto de Noé, con la de los Mudarras, dichoso injerto de las ramas de Cristo y Mahoma! Bien, bravísimo. Esto alivia, esto conforta. Completa sería la gloria de tal estirpe si viniera con dinero. [...] Me arrimo a la genealogía de mi abuelo materno, que tuvo el negocio de las harinas, y con este polvo, como decía en las cartas comerciales, amasó la riqueza que yo estoy desmigando ahora. Atrás Gustios y Mudarras, fuera el nieto de Noé, y viva mi Suárez, por donde, según tú, debo llamarme Asur, Hijo del Victorioso..., hijo del molinero, que, amparado del arancel, alimentó a tres generaciones de cubanos, y acá se traía las cajas de azúcar, que venían resudando el dulce. Yo me acuerdo. ¡Qué olor tan rico en aquellos almacenes, aroma de almíbares, mezclado con fragancia de canela; que allí había también fardos venidos de Ceylán! Llévate todos los chirimbolos de la caballería de Mudarra y tráeme mis almacenes de coloniales...jAh! También había cacao. América inocente nos mandaba mil primores cambiados por las harinas de acá... Las memorias de aquella riqueza se avivan en mi olfato. Huelo, huelo... ¿No hueles tú? ¡Ay!, los pergaminos de tus cronicones apestan a ranciedad putrefacta... Becerro, Becerro, apártate, hueles a ti mismo. Tráeme el árbol genealógico que tiene por hojas los billetes de banco, o no vengas ać. No me traigas la roña de tus archivos, cementerios de la nobleza pobre... La pobreza es muerte, joh gran Becerro ilustrado y vacío Becerro, sabio durmiente entre ratones! (92-93)

El contraste entre la visión eruditamente alejada de la realidad de Becerro y el materialismo de Gil-Tarsis no puede ser más agudo. Frente a la caballería de los Mudarras, Tarsis se posiciona del lado de los billetes de banco, estableciendo un claro contraste de evidente sabor cervantino.

En algunas ocasiones, la monomanía libresca de Becerro se convierte en un serio obstáculo para la vida. Cuando cae preso de la obsesión por la obra de Enrique de Villena, tradicionalmente asociado con la nigromancia, Becerro olvida las necesidades vitales más esenciales: comer y dormir. De hecho, cuando es visitado por Gil-Tarsis, Becerro expone las grandes ventajas de este modo de vida, capaz de eliminar las necesidades materiales para situarse en un mundo puramente ideal e intelectual: 
-Gracias, Asur-dijo el sabio sin tomar el dinero-. ¿Para qué te has molestado? El oro, la plata y los billetes, han llegado a serme indiferentes. Sabrás que ya no como... Todo es cuestión de acostumbrarse, de hacerse a no comer. Es una educación como otra cualquiera. Algún trabajo me ha costado adquirir este supremo hábito del perpetuo ayuno, de la emancipación del alma... ¿Sabes ya que me ocupo del marqués de Villena, primer apóstol de las ciencias físicas en España, y precursor de esa otra ciencia que nos enseña las leyes y fenómenos del universo suprasensible? [... No sé ya lo que es comer -dijo Augusto con sequedad de palabra y de intelecto-. Tan olvidado tengo el comer, que ya no sé cómo se come. Serías feliz como yo lo soy, querido Carlos, si llegaras a este perfecto estado, que trae, entre otros beneficios, el de la abolición radical de la Economía Política y otras ciencias vanas inventadas por los glotones. (IO4-I06)

El episodio dota a Becerro de un carácter profundamente quijotesco. $\mathrm{Al}$ igual que Oldbuck, Becerro sacrifica los aspectos materiales de su existencia en pos de una vida fundamentalmente libresca, alejada de las necesidades propias del resto de los seres humanos, subrayando la distancia cómica entre el erudito estrafalario y el resto de la sociedad. Esta dedicación absoluta a la erudición se ve a su vez confirmada por las abundantes y habitualmente absurdas empresas eruditas de Becerro, entre las que se encuentran la escritura de una obra enciclopédica sobre la presencia romana en Hispania, en la que Becerro dedicaría un tomo a cada uno de los generales romanos que el Imperio mandó para subyugar a Numancia (200), el intento de seguir el rastro de todas las hetairas que los romanos trajeron a Hispania (200), o la propuesta de exhumar los restos de Numancia en un sistema "perpendicular combinado" (20I) que le permitiría descubrir los distintos estratos de la ciudad, desde los asentamientos celtíberos hasta los tiempos de Trifón, hermano de Osiris (202). En este sentido, Becerro muestra una clarísima afinidad con el personaje de Oldbuck, ya que ambos eruditos viven una obsesión continua por desentrañar los orígenes históricos y arqueológicos de la realidad circundante, siendo el proceso de romanización de los pueblos pre-romanos de Iberia y Britania una obsesión común para ambos. 
Pese a su supuesta erudición histórica, las teorías de Becerro, amén de disparatadas, entran en numerosas ocasiones en claro conflicto con la veracidad histórica. De hecho, no son pocas las veces en las que el erudito quijotesco no es capaz de distinguir entre el acontecimiento histórico y la figuración literaria, cayendo en una confusión muy similar a la experimentada por Don Quijote, al no ser capaz de distinguir la fingida historicidad de los libros caballerescos de la realidad. Así ocurre en sus estudios sobre Enrique de Villena, en los que, enlazando una excentricidad histórica tras otra, Becerro acaba por dotar de carácter histórico al baladro de Merlín y sus encantamientos, explicitando de esta manera la poca distancia entre el personaje de Galdós y el Ingenioso Hidalgo, también propenso a cometer errores de interpretación historiográfica de carácter similar:

-No aceleres tu juicio, ni apliques dicterios infernales a este estado de felicidad perfecta. No interrumpas mis estudios, que ahora estoy en las apreturas de demostrar que el Rey Sabio don Alfonso X fue precursor de mi don Enrique de Villena, pues en su Libro de los juegos de ajedrez, dados et tablas dice que no se puede jugar bien al ajedrez sin saber de astrología. Lo mismo siente y declara el Maestre de Santiago en su Libro de Aojamiento y Fascinología, y ello concuerda... Verás-dijo esto tomando del rimero de la izquierda un gordo y mugriento librote, que abrió por un punto marcado-. Verás: este es el famosísimo y fundamental libro de Encantamientos, escrito por el propio Merlín en lengua bretona, y traducido al italiano por Messer Zorzí $[\ldots]$ Autores de más crédito, como el desconocido español que compuso $E l$ Baladro de Merlín, sienten y aseguran que éste no nació de ayuntamiento del diablo con doncella bretona, sino que un ángel le dio la existencia. No el trato con demonios, sino el estudio de la astrología, le dio su saber profundo de cuanto se refiere al destino del alma, y al estado de encantamiento o beatitud de las criaturas...Te diré que baladro es como alarido o voz espantosa, porque el gran Merlín, padre de la verdadera ciencia, fue encantado por su mujer, digamos manceba, llamada Bibiana, la cual volvió contra él la virtud o maleficio de un amuleto poderoso. De mujer no se podía esperar cosa buena. Quedó Merlín preso para siempre en la espesura de un bosque de Inglaterra, donde aún está, y cuanto se ha hecho para encontrarle ha sido inútil. Desde la profundidad de su encantamiento lanza de vez en cuando unos baladros o bramidos que se oyen a mil leguas a la redonda y hacen temblar toda la tierra. (I IO-I I I)

Finalmente, al igual que su compañero escocés en andanzas librescas, Becerro mostrará una clara tendencia a transformar eruditamente la realidad, 
completando o transformando su percepción del presente a través de sus lecturas en torno al pasado. Así ocurre en el tramo final de la novela, en el que Gil-Tarsis encuentra de nuevo a Becerro como empleado de las excavaciones de las ruinas de Numancia en Garray. Al igual que Oldbuck en el supuesto campamento romano de Agrícola, Becerro recrea imaginativamente el mundo de sus investigaciones históricas, interactuando con él en su locura libresca:

Sí, gracias a Dios... Estos aires, tan sanos como heroicos. .. , la Historia alta, y llamo alta a la que nos cuenta las virtudes máximas; la historia de altura es el mejor de los tónicos. Heme restablecido aquí. Ya no me queda más que un remusguillo del pasado achaque....Algunos días, cuando sopla ese viento que los griegos llamaban Apellotes, o aquel otro llamado Eurus, me siento un poquitín tocado. Ayer precisamente estuve todo el día estudiando la táctica y movimientos del primer expugnador de Numancia, Quinto Fulvio Novilio, el que trajo el escuadrón de elefantes... A estas bestias de gran calibre consagré yo mis cinco sentidos; las hice avanzar de tres en fondo sobre los numantinos; fijé el punto en que los animalitos, digo animalotes, se espantaron, y volviendo grupas de improviso, llevaron la confusión y el desorden al campo romano....Pues anoche... Verá usted...., salí a tomar el aire, y como de costumbre me alejé... campo adelante. Hallábame tan despierto como ahora lo estoy, puede creérmelo...¿Cuál no sería mi sorpresa al ver venir los elefantes desmandados, como le estoy viendo a usted ahora? Era un horror. Bajo las pisadas de aquellos monstruos temblaba la tierra... Quise huir, caí al suelo... Los terribles paquidermos pasaron sobre mí... .Imagínese usted... Cada una de sus patas pesaba como una torre...;Ay, ay! Testimonio de aquel desastre son los dolores que tengo en este lado, ¡ay! (200)

La distorsión libresca en la percepción de la realidad de Becerro se acentúa hacia el final de la obra, que otorga al personaje galdosiano un claro carácter trágico, abandonando los contornos cómicos con los que el novelista canario había caracterizado al erudito a lo largo de su novela. Tras ser despedido de su empleo en Garray por los recortes del gobierno, situación quizás harto conocida para los potenciales lectores de estas páginas, Becerro cae en la pobreza, y decide abandonar Soria para caminar a pie hasta Madrid, gozoso de poder "estudiar en tierra castellanas cuantas ruinas gloriosas [le] salieran al paso" (298). Por desgracia, justo a su salida de la localidad soriana, 
Becerro es asaltado y engañado por lo que él define como unos "alumnos de Anacreonte":

-Salí una mañana, y a las dos leguas plus minisque de mi salida de Garray, topé por mi desgracia con unos golfos, digamos más propiamente alumnos de Anacreonte, que en la puerta de un ventorro jugaban y reían con dos desconocidas hetairas, de la que expulsó Scipión, mandándolas con viento fresco a correr por el mundo. Ello fue que me engatusaron aquellos perdidos, y ellas me poparon y me hicieron mil carantoñas con manos perfumadas de olor sabeo. Debí perder mi natural sentido, o adormecerme en vapores de alegría, porque cuando la infernal caterva se alejó de mí, noté que me habían quitado la ropa y las veintidós pesetas... menos dos reales que había gastado en comprar pan... Dejáronme limpio de numerario, sin más tesoro que el inagotable de mi resignación...

-Pero usted, amigo mío, ipor qué se dejó zarandear de tal gentuza?díjole el caballero- ¿Eran acaso plebe celtíbera, o de la maleante familia de los pelendones?

-Para mí que eran túrdulos-replicó Becerro gravemente, de estos que se corren hacia el Norte para corromper a los austeros arévacos. (298-299)

La total confusión entre el saber erudito y la realidad dota al episodio de un carácter ciertamente cervantino. Princesas o mozas del partido, doncellas o hetairas, maleantes o túrdulos: todo se confunde en el universo libresco de Becerro, perdido en el laberinto de su erudición, que le llevará a acabar fusilado por la Guardia Civil en un episodio que Galdós moldea claramente tomando el célebre encuentro entre Don Quijote y los galeotes. ${ }^{20}$

${ }^{20}$ El carácter trágico que esta confusión epistemológica adquiere hacia el final de la novela se acentúa una vez que Becerro es detenido por la Guardia Civil por robar una cebolla:

No sé a dónde me llevan. Al cuadrillero que me interrogó por primera vez he dicho que mi deseo es ir a Madrid, pues allí tengo amigos que serán fiadores de mi honradez. No sé tampoco dónde estoy, ni si esto que parece quintana o mercado romano, algo semejante al zoco de los árabes, es buena dirección para Madrid, o si lo es para el Congo. ¿En qué país estamos? ¿Esto es España o es algo de otros mundos, de otros planetas, a donde de un puntapié nos ha mandado la mágica Astarté, diosa de los infiernos? (300)

A su vez, en un paralelismo delicioso por parte de Galdós, Becerro cree ser detenido por los caballeros de la Santa Hermandad cuando la Guardia Civil finalmente lo apresa (3 I4). Como castigo por su detención, los agentes de la Benemérita tendrán que soportar las disquisiciones eruditas de Becerro en su camino hacia Madrid: 
De los episodios anteriormente expuestos se deduce una clara posición crítica por parte de Galdós respecto a la erudición fútil, vana. En realidad, Galdós parece contraponer dos visiones bien distintas de la historia. Por una parte, la historia ciertamente erudita, pero apolillada y descontextualizada de Becerro. Por otra, la historia como memoria y continuidad de un pueblo, visión que Galdós epitomiza a través de la figura de la Madre, trasunto simbólico de España:

LA MADRE- Pues te decía que la maravilla de tu paso de un vivir a otro se debió a un oficioso entusiasmo de tu amigo Pepe Augusto Becerro, que quiso demostrarte con desusada pompa y ruido su afecto y su gratitud. Tiempo ha que practicaba la magia. No te asombres, Gil, si te digo que entre la magia y la erudición existe un entrañable parentesco: ambas artes toman su savia de la antigüedad remota. El erudito devorador de archivos se embriaga del zumo espirituoso contenido en los códices y acaba por poseer el don de suprema alucinación, de penetrar en el alma de las cosas y de sojuzgar el mundo físico. En el profundo estudio que hizo Becerro de los libros de caballería, llegó a sorprender el intríngulis magnético de las Urgandas y Merlines y el dinamismo prodigioso de Mandanfabul, de Famongomadán y otros apreciables gigantes. Metido luego en el laberinto del marqués de Villena, visitó el interior de sus redomas, y en ellas y en podridos pergaminos aprendió mil sutilezas. Yo te lo diré sin reparo: aunque soy tan vieja, mejor dicho, aunque en antigüedad no me gana nadie, siento poca simpatía por la erudición secamente erudita, quiero decir, por el saber de menudencias que maldito lo que interesan a la humanidad viva. A pesar de esto, las leyes de mi existencia me obligan a transigir hasta con los maniáticos, y a pasar algunos ratos en los archivos polvorosos y en las acartonadas academias... Y más de una vez he tenido que recurrir al sabio para que viniese en auxilio de mi memoria, que en el correr de tantos años y siglos suele flaquear y oscurecerse. «Pepito-le pregunto-. ¿En qué fecha vino Julio César a España por tercera vegada?» Y él me lo dice gustoso, y me cuenta después que traía la calva remediada por un gracioso artificio de su corto cabello. Otro día me cuenta que Sertorio se afeitaba solo, y que a Parpena le molestaban los sabañones. (I44-I45, énfasis añadido)

Como explicita la madre, la erudición excesiva no deja de ser una forma de alucinación, de visión quijotesca que aleja al estrafalario erudito

Primero entretuvo a los guardias contándoles el paso del Cid con toda su hueste por estos lugares, para ir a la conquista de Valencia... Después, metiéndose en la geografía arcaica, les dijo que no lejos de aquí tuvieron los celtíberos su celebrada Confluenta... y otras ciudades. (3I I) 
de la realidad y de la esencia de la historia, dirigiéndole a menudencias que poco tienen que ver con el presente. En realidad, Galdós parece querer contraponer la historia viva, que encuentra su reflejo en el pueblo, y la historia muerta de los archivos y becerros tan caros a Don José Augusto. De este modo, el novelista canario se sirve de la figura del erudito quijotesco para criticar una aproximación a la historia que la aleja irremisiblemente del presente, convirtiéndola en un saber anacrónico y de poca relevancia para el lector contemporáneo. Quizás su propia producción novelística, un intento de vincular el pasado inmediato con la contemporaneidad del autor, suponga la respuesta a esta erudición historiográfica que Galdós satiriza en su novela.

\section{Conclusiones}

Como he tratado de exponer a lo largo de estas páginas, The Antiquary y El caballero encantado evidencian un uso bastante similar de la figura del erudito quijotesco, de la que Scott y Galdós se sirven para cuestionar la erudición vacía e irrelevante, articulando sus propios posicionamientos frente a la historia y su empleo como materia para la obra literaria. De hecho, las claras concomitancias entre las figuras de Oldbuck y Becerro invitan a pensar en una posible influencia del autor escocés en la novela de Galdós. En su magnífico trabajo en torno a la figura del erudito anticuario en la novela de Scott y en Doña Perfecta y Narváez de Galdós, Lieve Behiels, aun reconociendo el interés del autor canario por el novelista escocés, rastreable gracias a la presencia de las obras completas de Scott en la biblioteca de su residencia santanderina (Chonon-Berkowitz i95 I: 190), subrayaba cómo la mera presencia de las obras de Scott en la biblioteca galdosiana no prueba que éste las llegara a leer (2017: 192). En cualquier caso, me parece que los claros paralelismos entre las figuras de Oldbuck y Becerro demuestran cómo Scott y Galdós llevan a cabo un uso afín de una figura ampliamente desarrollada por la tradición cervantina del siglo XVIII y a la que ambos au- 
tores dan nueva vida en el siglo XIX y a comienzos del siglo XX, hecho que ofrece motivos suficientes para posicionar al autor escocés como una posible influencia de primer orden para Galdós, tanto en su actitud particular respecto al pasado como en su aproximación hacia Cervantes y la figura del Quijote. Scott y Galdós muestran una clara oposición al pasado apolillado y acartonado de sus eruditos quijotescos, frente a los que parecen contraponer una visión de la historia con clara vocación de continuidad en el presente, reivindicándola como materia novelable. La similar funcionalidad de la figura del erudito quijotesco en la obra de ambos autores también debe, en mi opinión, fomentar una nueva aproximación a la cuestión de la influencia de Cervantes en Galdós, que hasta la fecha ha sido abordada de manera unidireccional, sin tener en cuenta la posible relevancia de otros autores deudores de Cervantes que también pudieron dejar su impronta en el uso de materiales cervantinos por parte del autor canario. Como he tratado de demostrar en otro lugar (2016), la recepción internacional de Cervantes no puede ser estudiada en toda su complejidad desde un paradigma binario que excluya a otros posibles mediadores entre Cervantes y el autor estudiado, sino que en muchos casos implica un proceso de intermediación literaria en el que se ven implicados terceros autores pertenecientes a la tradición cervantina. En este sentido, los ejemplos de Jonathan Oldbuck y José Augusto del Becero suponen una nueva confirmación del carácter proteico y profundamente transnacional que el mito de Don Quijote ha demostrado durante sus más de cuatrocientos años de andanzas por las literaturas europeas, así como de su función como catalizador de deliciosas afinidades electivas dentro de la historia de la literatura europea.

\section{BIBLIOGRAFÍA}

Behiels, Lieve (2016), "Los distintos modos de practicar la historia: Walter Scott y Galdós sobre los anticuarios" en La historia en la literatura española del siglo XIX. José Manuel González Herrán et al (Eds). Barcelona: Universidad de Barcelona, pp. 205-2 I 5.

Benítez, Rubén (1990), Cervantes en Galdós. Murcia: Universidad de Murcia. 
Berkowitz, Chonon H.(igs i), La biblioteca de Benito Pérez Galdós. Catálogo razonado precedido de un estudio. Las Palmas de Gran Canaria: El Museo Canario.

Cochrane, John G. (1 834), Catalogue of the Library at Abbotsford. Edinburgh: Constable.

Dorca, Toni (2016), "La nación en ciernes: La reescritura del Quijote en la primera serie de los Episodios Nacionales de Benito Pérez Galdós” en El Quijote y América. Eds. López Martínez, María Isabel y Montes Doncel, Rosa Eugenia. Sevilla: Renacimiento, pp. 37-5 5.

Dotras Bravo, Alexia (2013), "Influencias cervantinas en La desheredada de Benito Pérez Galdós" en $O$ seculo do romance. Eds. Lourenço, António Apolinário et al. Coimbra: Universidad de Coimbra, pp. 64I-653.

Elizalde, Ignacio (I99I), "Cervantes y las novelas galdosianas” en Actas del II Coloquio Internacional de la Asociación de Cervantistas. Barcelona: Anthropos, pp. 233-239.

Ferris, Ina (2002), "Pedantry and the Question of Enlightenment History: The Figure of The Antiquary in Scott”, European Romantic Review i 3.3, pp. 273-283.

FAlConieri, John V. (1972), "Un capítulo de Galdós que no se le olvidó a Cervantes". Revista de Estudios Hispánicos, 6. I, pp. I45-I 5 I.

Fernández de Azcarate, Sara Alicia (2010), El Quijote en Galdós. Intertextualidad en el mito de la identidad en cuatro novelas contemporáneas (188I-I884). Universitat de Barcelona, tesis doctoral inédita.

Frenzel, Elisabeth (1994), Diccionario de argumentos de la literatura universal. Madrid: Gredos.

Gerli, Michael (2005), “Pray landlord, bring me those books': Notes on Cervantes, Walter Scott and the Ethical Legitimacy of the Novel in Early Nineteenth Century England." Corónente tus hazañas: Studies in Honor of John Jay Allen. Ed. Michael J. McGrath. Newark: Juan de la Cuesta, pp. 23 I-43.

Goldman, Peter B. (1 97 I), "Galdós and Cervantes: Two articles and a fragment”. Anales Galdosianos 6, pp. 99-106.

Gullón, Germán (2004), "La presencia de Cervantes en Galdós”. Siglo diecinueve io- I I, pp. 33-4I.

Herman, Jack Chalmers (1955), Don Quijote and the Novels of Pérez Galdós. Ada: East Central Oklahoma State College.

Obaid, Antonio (1958), “Galdós y Cervantes”. Hispania 41.3, pp. 269-273.

Latorre, Mariano (I 947), "Cervantes y Galdós”. Atenea 58, pp. i I-40.

Mancing, Howard (2009), "The Quixotic Novel in British Fiction of the Nineteenth and Twentieth Centuries." The Cervantean Heritage: Reception and Influence of Cervantes in Britain. Ed. J. A. G. Ardila. Londres: Legenda, pp. I04-I7.

McDonald JR, W.U. (I959), “Scott's conception of Don Quixote.” Midwest Review, pp. 37-42.

Montero Reguera, José (201 8), "La habitación cerrada: una cala cervantina en la historia de la novela" en La pluma es la lengua del alma: Actas del IX Congreso Internacional de la Asociación de Cervantistas. Eds. Francisco Cuevas Cervera et al. Alcalá de Henares: Universidad de Alcalá de Henares, pp. 45-69.

Moro Martín, Alfredo (2016), Transformaciones del Quijote en la novela inglesa y alemana del siglo XVIII. Alcalá de Henares: Servicio de Publicaciones.

Moro Martín, Alfredo (2017), "Don Quijote y la novela histórica: consideraciones sobre la influencia cervantina en Waverley, or 'Tis Sixty Years Since (1 8 I 4), de Sir Walter Scott". Cervantes: Bulletin of the Cervantes Society of America 37.2, pp. I69-20I.

Müllenbrook, Heinz Joseph (1999), “Scotts Waverley als ‘Respons’ auf Cervantes’s Don Quixote.” Literaturwissenschaftliches Jahrbuch im Auftrage der Görres Gesellschaft, 40, pp. I 39- I 54.

Müller, Wolfgang (1988), "Sir Walter Scotts Waverley und die Don Quijote Tradition." Arcadia, 23, pp. I33-I 48 .

Pardo García, Pedro Javier (1998), "Don Quijote y los eruditos: sobre la sátira quijotesca de la pedantería en la literatura francesa del siglo XVIII" en Actas del Tercer Congreso Internacional de la Asociación de Cervantistas. Antonio Pablo Bernat Vistarini (Ed.). Palma de Mallorca, Universitat de les Illes Balears, Servei de Publicaciones i Intercanvi Científic, pp. I 49-I 57. 
Pardo García, Pedro Javier (2004), "Satire on Learning and the Type of the Pedant in EighteenthCentury Literature", BELLS: Barcelona English Language and Literature Studies, I 3, pp. I- I I.

Pardo García, Pedro Javier (20I4), "Viajeros quijotescos y viajes cervantinos en las letras británicas” en La cultura española en la Europa Romántica. Ed. José Checa Beltrán. Madrid: Visor Libros, pp. I 2 I-I 53.

Pardo García, Pedro Javier (2016), "Cervantes, Scott y el héroe quijotesco decimonónico". Erbea: Revista de Humanidades y Ciencias Sociales 6, pp. 109-I45.

Penas Varela, Ermitas (2013), La tercera serie de los Episodios Nacionales de Benito Pérez Galdós: quijotismo y romanticismo. Vigo: Academia del Hispanismo.

PÉrez Galdós, Benito (I 979), El caballero encantado. Madrid: Cátedra.

Rivero Iglesias, Carmen (2007), "Hofmann, Galdós y Keller: tres homenajes a Cervantes del siglo XIX" en Cervantes y el Quijote: Actas del coloquio internacional. Madrid: Arco Libros, pp. 319-330.

Rodríguez, César ( I 966), "La huella del Quijote en las novelas de Galdós”. La palabra y el hombre, 38 , pp. $223-263$.

Rodríguez Puértolas, Julio (1972), “Galdós y El caballero encantado”. Anales Galdosianos 7, pp. II7-I 29.

Scoтt, Walter (2009), The Antiquary. Oxford: Oxford University Press.

SNEL-Wolfe, Clara (1932), "Evidences of Scott's Indebtedness to Spanish Literature." The Romanic Review 23.4, pp. 30 I-I I.

Warshaw, J. (1933), “Galdós' indebtedness to Cervantes”. Hispania i6.2, pp. I 27 - I42.

Welsh, Alexander (198I), Reflections on the Hero as Quixote. Princeton: Princeton UP.

Wolpers, Theodor (1986), "Der romantische Leser als Kriegheld und Liebhaber: Poetisierung der Realität in Walter Scotts 'Waverley." Gelebte Literatur in der Literatur: Studien zur Erscheinungsformen und Geschichte eines literarisches Motivs. Ed. Theodor Wolpers. Gotinga: Vandenhöck, pp. I85-97

recibido: marzo de 2019

aceptado: junio de 2019 